Supporting information

\title{
A Compact ATR-WGS Integrated Bioethanol Fuel Processor for Portable and On-board Fuel Cell Applications
}

Yongmin Kim ${ }^{1, *}$, Yeonsu Kwak ${ }^{1}$, Yu-Jin Lee ${ }^{1}$, Young Suk Jo ${ }^{1}$, Hyuntae Sohn ${ }^{1}$, Hyangsoo Jeong ${ }^{1,4}$, Hyoung-Juhn Kim ${ }^{1}$, Jong Hee Han ${ }^{1,2}$, Suk Woo Nam ${ }^{1}$, Chang Won Yoon ${ }^{1,3,4, *}$

${ }^{1}$ Center for Hydrogen Fuel Cell Research, Korea Institute of Science and Technology, Seoul 02792, Republic of Korea

${ }^{2}$ Green School, Korea University, Anam-ro 145, Seongbuk-gu, Seoul, 02841, Republic of Korea

${ }^{3}$ KHU-KIST Department of Converging Science and Technology, Kyung Hee University, Seoul 02447, Republic of Korea

${ }^{4}$ Division of Energy and Environment Technology, KIST School, Korea University of Science and Technology, Seoul 02792, Republic of Korea

* Corresponding authors, e-mail: yongminkim@kist.re.kr, cwyoon@kist.re.kr

Number of pages: 3

Number of figures: 2

Number of tables: 1 


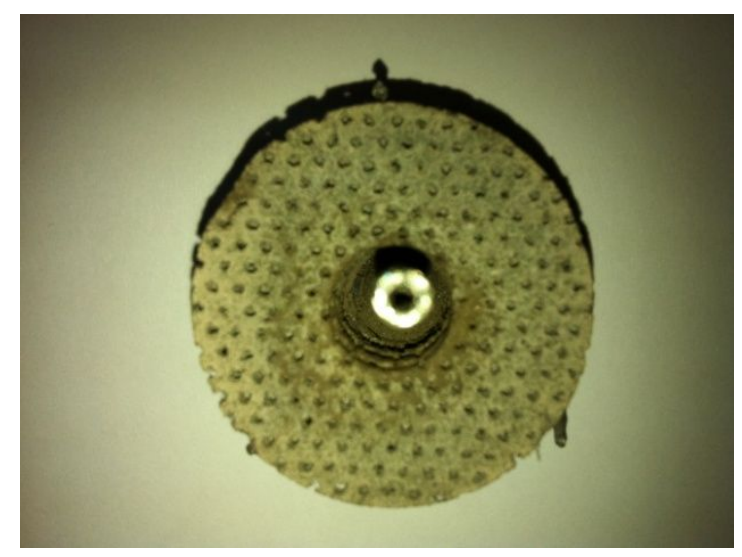

Figure S1. A picture of the Rh-GDC coated structured catalyst positioned at the ATR reactor after the $700 \mathrm{~h}$ continuous operation. 


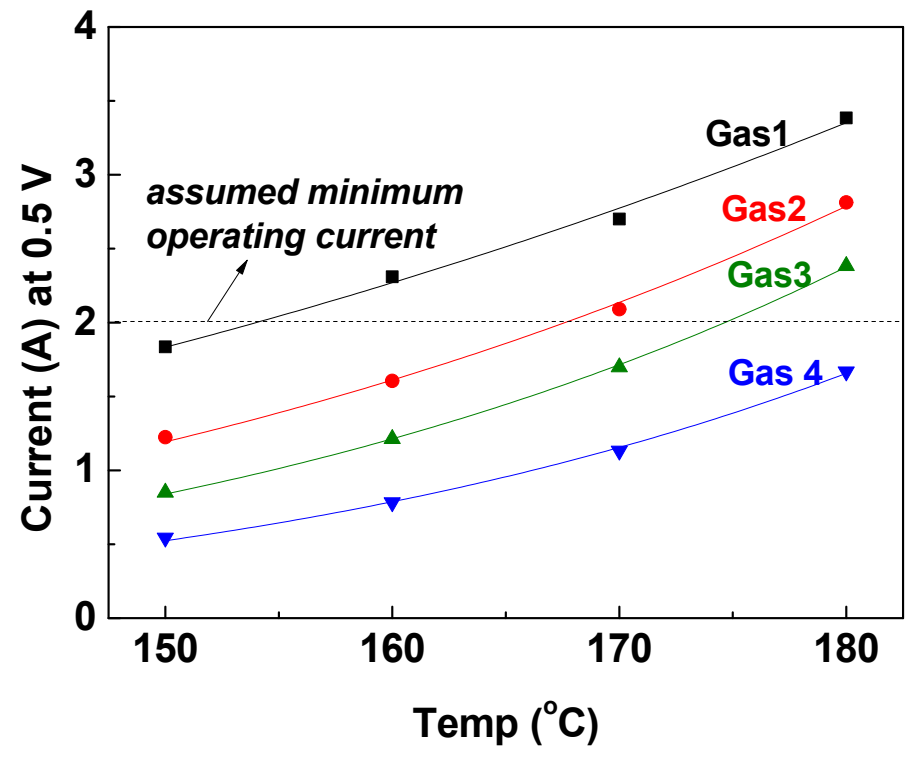

Figure S2. The current of the HTPEMFC single cell at $0.5 \mathrm{~V}$ as a function of temperature and different $\mathrm{CO}$ concentration in the reformate gas and temperature. The active area of the electrode was $25 \mathrm{~cm}^{2}$. The dot-line denotes the assumed minimum operating current. Table S1 represent gas compositions and flow rates of Gas 1-4.

Table S1. Gas compositions and flow rates of Gas1, Gas2, Gas3 and Gas4 used in operating the HTPEMFC single cell.

\begin{tabular}{|c|c|c|c|c|c|c|}
\hline \multicolumn{2}{|c|}{} & $\mathbf{H}_{\mathbf{2}} \mathbf{O}$ & $\mathbf{H}_{\mathbf{2}}$ & $\mathbf{N}_{\mathbf{2}}$ & $\mathbf{C O}_{\mathbf{2}}$ & $\mathbf{C O}$ \\
\hline \multirow{4}{*}{$\begin{array}{c}\text { Molar } \\
\text { concentration } \\
(\mathbf{m o l} \%)\end{array}$} & Gas1 & 29.2 & 28.9 & 27.3 & 14.4 & 0.2 \\
\cline { 2 - 7 } & Gas2 & 30.1 & 28.0 & 27.3 & 13.5 & 1.0 \\
\cline { 2 - 7 } & Gas3 & 31.2 & 27.0 & 27.3 & 12.4 & 2.1 \\
\cline { 2 - 7 } & Gas4 & 34.2 & 23.9 & 27.3 & 9.4 & 5.1 \\
\hline \multirow{3}{*}{$\begin{array}{c}\text { Gas flow rate } \\
(\text { sccm) }\end{array}$} & Gas1 & 151 & 149 & 141 & 74 & 1 \\
\cline { 2 - 8 } & Gas2 & 155 & 145 & 141 & 70 & 5 \\
\cline { 2 - 8 } & Gas3 & 161 & 139 & 141 & 64 & 11 \\
\cline { 2 - 7 } & Gas4 & 177 & 123 & 141 & 48 & 27 \\
\hline
\end{tabular}

